\title{
Digital Payments Adoption: An Analysis of Literature
}

\author{
Pushp P. Patil, Yogesh K. Dwivedi ${ }^{1}$, Nripendra P. Rana \\ Emerging Markets Research Centre (EMaRC), School of Management, Swansea University \\ Bay Campus, Swansea, SA1 8EN, UK \\ \{Email: Pushpppatil@gmail.com; y.k.dwivedi@Swansea.ac.uk; \\ n.p.rana@swansea.ac.uk\}
}

\begin{abstract}
Digital payments (mainly enabled by mobile devices) have huge potential to change lives of millions of people in developing countries by offering financial services to the unbanked masses. Despite its potential digital payment methods have not been widely and successfully adopted in the developing countries. In order to ascertain the various drivers and inhibitors behind digital payment adoption, this study did a review of research on digital and mobile payment adoption and use. Results of this literature analysis revealed performance expectancy/perceived usefulness as most significant determinant of consumer's behavioral intention to use mobile payments followed by perceived ease of use (PEOU). Perceived risk was found as major inhibitor to the adoption of mobile payments. Also majority of studies employed TAM and its extension to understand consumer adoption to mobile payment followed by UTAUT.
\end{abstract}

Keywords: Adoption, Cashless Payments, Digital Payments, Diffusion, Literature Review, Mobile Payments, TAM, UTAUT

\section{Introduction}

Internet has changed the way business is conducted in recent years in terms of wireless communication. This emerging trend is more powerful than anything internet used to offer before as this allows consumers an anywhere and anytime paradigm [1]. In the history of mankind no other innovation has influenced the lives of people in ways as Mobile devices [2]. These hand held devices have gradually shifted daily activities from real world circumstances to mobile phone-based virtual world. In the entire consumer technology adoption history the rate of adoption of Mobile phone was the fastest and to the deepest level [3].

The global spread and use of mobile devices provide prominent role to digital payments in the payment market. This wide penetration of mobile devices bring world of opportunities to transform the manner in which people manage and move money through secure mobile transactions [4]. Consumers are slowly moving towards changing their payment method from traditional ways to contactless devices due to emergence of these new mobile and other digital payment technologies. The rapid development in technology has enabled innovation in payment methods resulting in

\footnotetext{
${ }^{1}$ Corresponding author
} 
applications such as Near Field Communication (NFC), mobile wallets, P2P apps, quick response code and wearable [5].

Despite their popularity as an emerging service mobile payments have not as widely adopted as expected in the developing countries [4]. This could to attribute to the fact that in the developed countries Mobile Payment systems have to compete with range of alternative payment methods with longstanding history [6]. However, the scenario is quite different in the emerging markets. Mobile Payments are readily accepted in the countries like Kenya and Philippines where penetration of formal banking system is low [7].

Given the background, it is undoubted mobile payments have potential to bring financial inclusion especially in the emerging markets by offering financial services to the unbanked masses and improve their lives for better. Recently there have been huge drives to promote various digital payment systems including mobile payments by Government of India (GoI) for enhancing transparency in financial transactions, reducing tax envision and improving public welfare and delivery systems. GoI has not only made variety of digital payment systems available to cater need of all segments (affluent vs. non affluent; rural vs. urban) of society, but widespread training and financial incentives also offered to equip and encourage people to use these systems. Despite the advantages of digital payment systems and widespread promotion there is reluctance among consumers to use various digital payment systems including mobile payment not only in India but also in other countries. This provides motivation and relevance to undertake research in this area. An examination of existing literature suggest that a number of studies have already been conducted to examine factors influencing mobile payments adoption largely in the context of developed countries and there are some in developing countries context. Before undertaking any further empirical work on this topic, it was deemed appropriate to undertake review of existing studies for synthesizing the results reported, identifying their limitations and directions of further work in this important and emerging area.

Considering the discussion presented above, the aim of this study is to undertake analysis and synthesis of relevant research exist on issues related to the mobile payments adoption. In order to achieve this, the remaining part of this submission is structured as follows: next section briefly describe literature search and analysis approach followed by a brief review relevant studies is presented in Section 3. Section 4 briefly outlines the main limitations of existing work followed by future research directions in Section 5 and finally, key conclusions are outlined in the last section.

\section{Literature Search Approach}

It was deemed appropriate to do keyword search in order to achieve objectives of this research. This study utilized following keywords to undertake search for relevant work using the Scopus database: "Digital Payment" OR "Cashless Payment" OR "Mobile Payment" OR "Adoption" OR "Acceptance" OR "Diffusion" OR "Usage" OR "Intention" OR "Success" OR "Satisfaction" in order to identify papers relevant to digital payment. The keyword search returned 109 articles. We were able to download 47 full articles. Then Adobe Reader's advanced search function was 
employed using keywords such as "consumer" and "adoption" for all 47 full articles on mobile payment in order to narrow down articles on consumer adoption of mobile payment. The downloaded mobile payment articles were deemed to be relevant for this study if they met one of the following two criteria: (1) the data collection of research took place among consumers, or (2) the studies developed conceptual model to be empirically tested on consumers at later stage. The articles were screened out if the data was collected from merchants or focusing on organizations aspect. In the end 21 papers were found relevant for inclusion in this review. This study looked into these 21 articles which specifically focused on consumer adoption of mobile payment. Then a detailed review of these articles was conducted to identify theories utilized in this area and various drivers and inhibitors of mobile payment.

\section{Systematic Literature and Findings}

This section presents review summary of mobile payment adoption research. The review is classified broadly under two categories: 1) frequently used theories in research addressing consumer adoption of mobile payment; and 2) drivers and inhibitors of mobile payment adoption.

\subsection{Frequently used theories in consumer Mobile payment adoption}

A large number of Information Technology (IT)/Information Systems (IS) projects and systems continue to fail leading to adverse impact of such investments on individuals, organizations and society $[8,9,10]$. This provides reasonable impetus to researchers for repeatedly examining factor influencing adoption and use of new technologies and systems in the contexts of individual, organization and society. Consequently, multiple theories have been employed in IS field to determine individual technology acceptance in various use contexts. Table 1 reveals frequently used theories for understanding issues related to consumer adoption of mobile payment systems. These studies were either used standalone or in combination with other dominant technology adoption theories and models.

With 14 studies Technology Acceptance Model (TAM) and its extension have been most utilized technology adoption theory/model in this domain. These studies adopted, adapted and extended TAM across various use contexts. For instance the study by Augsburg \& Hedman [2] utilized TAM alongside with Innovation Diffusion Theory (IDT) to explore adoption of mobile payments and value added services (VAS). Whereas Zhang et al. [11] employed TAM standalone to explore factors affecting the adoption of mobile payment in particular cultural settings. The Unified Theory of Acceptance and Use of Technology (UTAUT) emerged as the second most utilized theory (originating from Venkatesh et al. [34]) with five studies employing it. Slade et al. [6] utilized UTAUT to examine consumer adoption of proximity mobile payments in the UK and Zhong et al. [11] utilized it to examine consumer adoption of mobile payments in China. This is followed by Diffusion of Innovation Theory (DOI) utilized thrice in studies including Pham \& Ho [12] who examined consumer adoption of NFC-based mobile payments. IDT was employed on two occasions by Augsburg \& 
Hedman [4] and Zhong et al. [11]. More than 50\% of studies reviewed by Slade et al. [20] have drawn on Davis' (1989) TAM as a theoretical base.

The remaining four theories/models were employed only once. The study of Keramati et al. [13] employed combinative model of Mallat N. factors (2007) [14] and Dahlberg and Oorni Factor model (2007) [35] to explore factors affecting 'mobile'-payment services adoption, whereas Kapoor et al. [15] utilized Tornatzky and Klein's theory and Moore and Benbasat's perceived characteristics of innovating theory to determine adoption of the interbank mobile payment service and finally Gong et al. [16] utilized trust based acceptance model to study the effects of cognitive and emotional trust on mobile payment adoption.

Table 1. Frequently used theories and model in consumer Mobile payment adoption.

\begin{tabular}{|l|c|l|}
\hline Theory/Model & Freq & \multicolumn{1}{|c|}{ Citations } \\
\hline TAM & 14 & $\begin{array}{l}{[4],[11],[17],[21],[22],[23],[24],} \\
{[25],[26],[27],[28],[29],[30],[33] .}\end{array}$ \\
\hline UTAUT & 5 & {$[6],[19],[20],[21],[33]$} \\
\hline DOI & 3 & {$[12],[15],[19]$} \\
\hline IDT & 3 & {$[4],[15],[33]$} \\
\hline Mallat (2007) & 1 & {$[13]$} \\
\hline Dahlberg and Oorni Factor (2007) & 1 & {$[15]$} \\
\hline Tornatzky \& Klein (1982) & 1 & {$[16]$} \\
\hline $\begin{array}{l}\text { Trust based acceptance model [38] } \\
\text { LEGEND: DOI: Diffusions of Innovations Theory; IDT: Innovation Diffusion } \\
\text { Theory; TAM: Technology Acceptance Model; UTAUT: Unified Theory of } \\
\text { Acceptance and Use of Technology }\end{array}$ \\
\hline
\end{tabular}

\subsection{Drivers and Inhibitors of Mobile Payment Adoption}

Review also revealed that majority of the studies have reported performance expectancy (PE) construct from UTAUT and perceived usefulness (PU) from TAM as most significant determinant of consumer's behavioral intention to use mobile payments whereas perceived risk was found as inhibitor to the adoption of mobile payments. Study of Augsburg \& Hedman [4] on value added services (VAS) and adoption of mobile payments found PU can influence the consumer intention to adopt mobile payments. Consumers see payment process being easier and more efficient when VAS is integrated with the mobile payment service. Compatibility and convenience were also found as critical factors of intention to adopt mobile payments [4].

Other studies that have reported PE/PU as major predictor of consumer mobile payments were Chandrasekhar \& Nandagopal [17]; Koenig-Lewis et al. [18]; Oliveira et al. [19]; Pham \& Ho [12]; Slade et al. [20]; Slade et al. [21]. Apart from PU the study of Chandrasekhar \& Nandagopal [17] found consumers will adopt mobile 
payment use behavior if it fits into their lifestyle. Whereas Koenig-Lewis et al. [18] study revealed social influence and perceived enjoyment can reduce perceived risk of using mobile payment.

Four studies [22], [23], [13], [24] have reported Perceived Ease of Use (PEOU) as major driver to consumer mobile payment adoption. These studies found in terms of consumers' willingness to adapt to mobile payment, the impact of usability issues are more important than those pertaining to usefulness. In addition to PEOU, the study of [23] noted that implementation of mobile payment technology needs substantial considerations in terms of infrastructure availability, partnerships between various stakeholders such as banks and phone operators and quality of the business model. Whereas, Keramati et al. [13] revealed an interesting lifestyle as a driver for adoption, finding people who travel often and reside in other countries are more inclined to use M-payment services.

Apart from PEOU and PU the following studies found other significant drivers of consumer mobile payment adoption. Liébana-Cabanillas et al. [25] and LiébanaCabanillas et al. [26] have reported role of external influence (that is derived from the social influence and subjective norms) as the strongest driver of consumer adoption towards mobile payment. Gao \& Waechter [27] found perceived information quality, perceived system quality, and perceived service quality as major drivers of initial trust formation while examining user adoption of mobile payment services. Emotional trust was found to have stronger effect on consumers' intention to use mobile payment [16]. Moreover, Hossain \& Mahmud [28] results found cognitive style significantly related to perceived ease of use in determining mobile payment adoption. Whereas Kapoor et al. [15] found Rogers' diffusion of innovation attributes as significant predicator for determining adoption of the interbank mobile payment service in India and Lee et al. [29] found perceived benefits as significant factor of mobile payment service acceptance.

Perceived risk (PR) was found as inhibitor by majority of the studies. Andreev et al. Andreev et al. [22] found PR as a major inhibitor of user willingness to M-Pay for LBS. They also found magnitude of PR's negative impact could be at least twice the magnitude of any other positive driver's impact. Apart from Andreev et al. [22] studies such as Koenig-Lewis et al. [18], Liébana-Cabanillas et al. [25], Pham \& Ho [12], Slade et al. [20] and Slade et al. [6] also found Perceived risk as the major inhibitor to consumer adoption to mobile payment. Whereas, Augsburg \& Hedmann [4] found an interesting fact that insignificant effect of VAS on Perceived Ease of Use can become an inhibitor. Apart from PR, perceived uncertainty was found as major initial trust inhibitor that exerts a significant negative effect on building initial trust in user adoption of mobile payment services. Information privacy is another inhibitor to consumer adoption of mobile payment services for "fintech". Whereas network externalities, security, and payment transaction information were found as major inhibitors to consumers 'mobile'-payment services adoption by Keramati et al. [13]. 


\section{Research Limitations}

Augsburg \& Hedman [4] research on value added service (VAS) and mobile payment have chosen three VAS but does not differentiate between them and presents them all to the experimental group. Limitation of this study is that VAS offer different value propositions and different consumers may be more attracted to some propositions than others. Gao \& Waechter [27] examined the role of initial trust in user adoption of mobile payment service empirically in Australia which, in terms of national characteristics, is different from other mobile technology advancing nations such as South Korea, Japan, and Finland. Also, the results of this study may or may not be applicable to emerging markets context such as India. Individual user characteristics is also a factor which might affect but not been used in this study. The study examined initial trust formation, which may demonstrate different trust behavioral pattern with time in future [27]. Gong et al. [16] examined the effects of cognitive and emotional trust on mobile payment adoption. The limitation of this study Gong et al. [16] is that sample size was relatively small and participants were Chinese university students or faculties, which require further research in different regional/national settings with a larger sample size. Hossain \& Mahmud [28] studied influence of cognitive style on mobile payment system adoption with an extended technology acceptance model. The limitation of this study is that sample size is too small and study used questionnaire which was completed by educated people with prior use experience of mobile payment. Another limitation of this study Hossain \& Mahmud [28] is that it has not examined actual usage behavior.

Kapoor et al. [15] examined role of three sets of innovation attributes for determining adoption of the interbank mobile payment service. The limitation of this study is that the data collection was geographically restricted to only four largest Indian cities. Given that the culture and geographical locations do impact the diffusion of an innovations, Kapoor et al. [15] work should be tested using data from smaller cities. Kim et al. [24] studied the adoption of mobile payment services for "fintech" and the limitation of this study is that the samples of the survey were limited to Seoul, the capital area, and certain age groups were predominantly represented, giving way to regional and age biases. Liébana-Cabanillas et al. [25] examined antecedents of the adoption of the new mobile payment systems with moderating effect of age. Limitation of this study is that it was focused only on one mobile payment system (SMS), while there are other technologies such as the NFC payment systems that also need attention. Oliveira et al. [19] examined mobile payment to understand the determinants of customer adoption and intention to recommend the technology. Limitation of this study is that it hasn't used some factors that some may consider important to the adoption of mobile payment, such as trust [30], [31] and risk [32]. Limitation of this research also concerns the age and location of the questionnaire respondents; more than $88 \%$ were aged 45 years or less from Portugal. 


\section{Future Research Directions}

Augsburg \& Hedman [4] was conducted in Denmark, which has very high mobile usage and very high maturity in credit and debit card usage; hence the high intention to use mobile payment with or without VAS is not surprising. Further research can focus in Western countries as well as in the context of emerging markets (such as India) with high cash usage. Gao \& Waechter [27] study suggest that future research should compare pre-adoption and post-adoption of m-payment trust behavior to find out whether trust behaviors changes over time. Gao \& Waechter [27] also recommended examining role of additional constructs such as perceived value, perceived justice and perceived risk. Gong et al. [16] study primarily focuses on the trust transfer mechanism from one source (web payment) to mobile payment (MP) as one target. This study only examined the effects of emotional trust in web payment, perceived similarity, and cognitive trust in MP on emotional trust in MP. As emotional trust in really important in consumer decision-making, future studies could empirically examine other valid mechanisms to build consumers' emotional trust in MP [16].

Hossain \& Mahmud [28] recommended undertaking further research in the context of rural areas in Bangladesh and testing an extended model by incorporating the actual usage, cognitive style or any other relevant variables based on the recent literature on this topic. Kapoor et al. [15] study can be extended by collecting more representative data from other states and smaller towns. The future studies may want to focus more on the influences of image as an innovation attribute. Also, the future studies might want to test the various risk types associated to IMPS in order to arrive at a more convincing explanation on the influences that riskiness may have on the diffusion of IMPS in the Indian context [15].

Follow-up studies to Kim et al. [24] should analyze the impact on the acceptance of groups classified into more specific age groups, income and device through a multi-group model. Future research of Liébana-Cabanillas et al. [26] can be directed towards in various technologies such as QR codes, a two dimensional bar code, biometric fingerprints, voice payment, Google Goggles. Oliveira et al.'s [19] work can be furthered by examining age and cultural differences. Studies with a larger sample size from other geographical settings can help to confirm validity and establish generalizability of Pham \& Ho [12]. Longitudinal studies should be conducted in future to test same research model at different points of time, which will allow comparisons and will help to provide further insights towards consumers' adoption behavior towards NFC mobile payments. In addition, the future research should also validate the modified UTAUT model developed by some recent studies (e.g. Dwivedi et al. [39, 40]; Rana et al. [41, 42]) in the areas of technology and egovernment adoption.

\section{Conclusions}

This study conducted a review of literature on consumer adoption of mobile payments. The salient points emerged from this literature analysis suggest that TAM 
and its extension as most utilized technology adoption theory/model for understanding consumer adoption of mobile payments. Performance expectancy and perceived usefulness emerged as most significant determinant of consumer's behavioral intention to use mobile payments whereas perceived risk was found as inhibitor to the adoption of mobile payments in majority of studies.

Although this review presents a concise summary of mobile payment adoption research, insight provide by it should be interpreted in light of the following limitations. This review was based on literature search using only Scopus database, so studies that are not indexed in this database may have been excluded. Future literature reviews should consider other databases to address the limitations of this study. Also, only a subset of studies identified was reviewed, remaining studies would be reviewed in this ongoing work to explore if there are drivers and inhibitors that needs to be considered by future studies. Also, this study only presented review about theories; drivers and inhibitors, there are other aspects that require further detailed analysis. This work mainly reviewed studies on mobile payment adoption; future reviews should also include studies on other digital payment methods. The other limitation is that this study focused on consumer adoption of mobile payment excluding organization adoption and other stakeholders.

\section{References}

1. Barnes, S.: The mobile commerce value chain: analysis and future developments. International Journal of Information Management. 22(2), 91--108 (2002)

2. Jack, W., Suri, T.: Mobile money: The economics of M-PESA (No. w16721). National Bureau of Economic Research (2011)

3. Thakur, R., Srivastava, M.: Adoption readiness, personal innovativeness, perceived risk and usage intention across customer groups for mobile payment services in India. Internet Research. 24(3), 369--392 (2014)

4. Augsburg, C., Hedman, J.: Value added services and adoption of mobile payments. Sixteenth International Conference on Electronic Commerce (2014)

5. De Kerviler, G., Demoulin, N., Zidda, P.: Adoption of in-store mobile payment: Are perceived risk and convenience the only drivers?. Journal of Retailing and Consumer Services, 31, 334--344 (2016)

6. Slade, E., Williams, M., Dwivedi, Y., Piercy, N.: Exploring consumer adoption of proximity mobile payments. Journal of Strategic Marketing, 23, 209--223 (2014)

7. Mobile financial services development report: http://www3.weforum.org/docs/ WEF_MFSD_Report_2011.pdf, (2011).

8. Dwivedi, Y., Wastell, D., Laumer, S., Henriksen, H., Myers, M., Bunker, D., Elbanna, A., Ravishankar, M., Srivastava, S.: Research on information systems failures and successes: Status update and future directions. Information Systems Frontiers, 17, 143--157 (2014)

9. Hughes, D., Dwivedi, Y., Rana, N., Simintiras, A.: Information systems project failure analysis of causal links using interpretive structural modelling. Production Planning \& Control, 27, 1313--1333 (2016)

10. Hughes, D., Dwivedi, Y., Simintiras, A., Rana, N.: Success and failure of IS/IT projects. Springer, Cham, Switzerland (2016)

11. Zhanga, A., Yue, X., Kong, Y.: Exploring culture factors affecting the adoption of mobile payment. Tenth International Conference on Mobile Business, 263--267 (2011) 
12. Pham, T., Ho, J.: The effects of product-related, personal-related factors and attractiveness of alternatives on consumer adoption of NFC-based mobile payments. Technology in Society, 43, 159--172 (2015)

13. Keramati, A., Taeb, R., Larijani, A., Mojir, N.: A combinative model of behavioural and technical factors affecting 'Mobile'-payment services adoption: an empirical study. The Service Industries Journal, 32, 1489--1504 (2012)

14. Mallat, N.: Exploring consumer adoption of mobile payments - A qualitative study. The Journal of Strategic Information Systems. 16, 413--432 (2007)

15. Kapoor, K., Dwivedi, Y., Williams, M.: Examining the role of three sets of innovation attributes for determining adoption of the interbank mobile payment service. Information Systems Frontiers, 17, 1039--1056 (2014)

16. Gong, X., Zhang, K. Z., Zhao, S. J., Lee, M. K.: The Effects of Cognitive and Emotional Trust on Mobile Payment Adoption: A Trust Transfer Perspective. In Proceedings of Pacific Asia Conference on Information Systems (PACIS), Taiwan (2016)

17. Chandrasekhar, U., Nandagopal, R.: Mobile Payment Usage Intent in an Indian Context: An Exploratory Study. Asian Journal of Information Technology, 15(3), 542--552 (2016)

18. Koenig-Lewis, N., Marquet, M., Palmer, A., Zhao, A.: Enjoyment and social influence: predicting mobile payment adoption. The Service Industries Journal. 35, 537--554 (2015)

19. Oliveira, T., Thomas, M., Baptista, G., Campos, F.: Mobile payment: Understanding the determinants of customer adoption and intention to recommend the technology. Computers in Human Behavior. 61, 404--414 (2016)

20. Slade, E., Dwivedi, Y., Piercy, N., Williams, M.: Modeling Consumers' Adoption Intentions of Remote Mobile Payments in the United Kingdom: Extending UTAUT with Innovativeness, Risk, and Trust. Psychology \& Marketing. 32, 860--873 (2015)

21. Staykova, K., Damsgaard, J.: Adoption of Mobile Payment Platforms: Managing Reach and Range. Journal of theoretical and applied electronic commerce research. 11, 66--85 (2016)

22. Andreev, P., Pliskin, N., Rafaeli, S.: Drivers and Inhibitors of Mobile-Payment Adoption by Smartphone Users. International Journal of E-Business Research. 8, 50--67 (2012)

23. Berrado, A., Elfahli, S., El Garah, W.: Using data mining techniques to investigate the factors influencing mobile payment adoption in morocco. Paper presented at the 2013 8th International Conference on Intelligent Systems: Theories and Applications, SITA, doi:10.1109/SITA.2013.6560791 (2013)

24. Kim, Y., Park, Y. J., Choi, J.: The Adoption of Mobile Payment Services for "Fintech". International Journal of Applied Engineering Research, 11(2), 1058--1061(2016)

25. Liébana-Cabanillas, F., Sánchez-Fernández, J., Muñoz-Leiva, F.: Antecedents of the adoption of the new mobile payment systems: The moderating effect of age. Computers in Human Behavior. 35, 464--478 (2014)

26. Liébana-Cabanillas, F., Sánchez-Fernández, J., Muñoz-Leiva, F.: The moderating effect of experience in the adoption of mobile payment tools in Virtual Social Networks: The mPayment Acceptance Model in Virtual Social Networks (MPAM-VSN). International Journal of Information Management. 34, 151--166, (2014)

27. Gao, L., Waechter, K.: Examining the role of initial trust in user adoption of mobile payment services: an empirical investigation. Information Systems Frontiers. 19, 525--548, (2015)

28. Hossain, R., Mahmud, I.: Influence of cognitive style on mobile payment system adoption: An extended technology acceptance model. Paper presented at the 2016 International Conference on Computer Communication and Informatics, ICCCI, doi:10.1109/ICCCI.2016.7479973 (2016)

29. Lee, J. B., Lee, S. B., Park, C.: A Study on the Individual and Environmental Factors Affecting Mobile Payment Service Acceptance-A Focus on NFC-based Payment ServicesJae-Beom. International Information Institute (Tokyo). Information, 18(4), 1185 (2015) 
30. Liébana-Cabanillas, F., Muñoz-Leiva, F., Sánchez-Fernández, J.: Influence of age in the adoption of new mobile payment systems. Revista Brasileira de Gestão de Negócios, 17(58), 1390 (2015)

31. Guillén, A., Herrera, L., Pomares, H., Rojas, I., Liébana-Cabanillas, F.: Decision Support System to Determine Intention to Use Mobile Payment Systems on Social Networks: A Methodological Analysis. International Journal of Intelligent Systems. 31, 153--172, (2015)

32. Slade, E., Williams, M., Dwivedi, Y.: Devising a research model to examine adoption of mobile payments: An extension of UTAUT2. The Marketing Review. 14, 310--335 (2014)

33. Zhong, J., Dhir, A., Nieminen, M., Hämäläinen, M., Laine, J.: Exploring consumer adoption of mobile payments in china. Paper presented at the Proceedings of the 17th International Academic MindTrek Conference: "Making Sense of Converging Media", MindTrek, 318--325 (2013)

34. Venkatesh, V., Morris, M. G., Davis, G. B., Davis, F. D.: User acceptance of information technology: Toward a unified view. MIS Quarterly, 27(3), 425--478 (2003)

35. Dahlberg, T., Oorni, A.: Understanding changes in consumer payment habits-do mobile payments and electronic invoices attract consumers? 40th Annual Hawaii International Conference on System Sciences (2007)

36. Moore, G. C., Benbasat, I.: Development of an instrument to measure the perceptions of adopting an information technology innovation. Information systems research, 2(3), 192-$222(1991)$

37. Tornatzky, L. G., Klein, K. J.: Innovation characteristics and innovation adoptionimplementation: A meta-analysis of findings. IEEE Transactions on engineering management, 1, 28--45 (1982)

38. Komiak, S. Y., Benbasat, I.: The effects of personalization and familiarity on trust and adoption of recommendation agents. MIS quarterly 30(4), 941--960 (2006)

39. Dwivedi, Y.K., Rana, N.P., Jeyaraj, A., Clement, M., Williams, M.D. Re-examining the Unified Theory of Acceptance and Use of Technology (UTAUT): Towards a Revised Theoretical Model. Information Systems Frontiers, DOI: 10.1007/s10796-017-9774-y, (2017a)

40. Dwivedi, Y.K., Rana, N.P., and Janssen, M., Lal, B., Williams, M.D., Clement, M.: An Empirical Validation of a Unified Model of Electronic Government Adoption (UMEGA). Government Information Quarterly, DOI: 10.1016/j.giq.2017.03.001, (2017b)

41. Rana, N.P., Dwivedi, Y.K., Lal, B., Williams, M.D., Clement, M.: Citizens' Adoption of an Electronic Government System: Toward a Unified View. Information Systems Frontiers, 19(3), 549--568 (2017)

42. Rana, N.P., Dwivedi, Y.K., Williams, M.D., Weerakkody, V.: Adoption of Online Public Grievance Redressal System in India: Toward Developing a Unified View. Computers in Human Behavior, 59, 265--282 (2016) 